\title{
A Pluralistic Account of Degrees of Control in Addiction
}

(forthcoming in Philosophical Studies. Accepted 4.24.2021)

Federico Burdman

Universidad de Los Andes

Abstract: While some form of loss of control is often assumed to be a common feature of the diverse manifestations of addiction, it is far from clear how loss of control should be understood. In this paper, I put forward a concept of decrease in control in addiction that aims to fill this gap and thus provide a general framework for thinking about addictive behavior. The development of this account involves two main steps. First, I present a view of degrees of control as the degree to which an agent would be responsive to potential or counterfactual sufficient reasons to do otherwise. Second, I sketch an account of the relevant controlundermining factors in addiction that is consonant with my proposed view of degrees of control. Being a high-level functional property, reasons-responsiveness is particularly well suited to frame an account of control-undermining factors that is doubly pluralistic: it encompasses the contribution of factors both internal and external to the agent, and it is consistent with various proposals as to the precise nature of the anomaly taking place in the psychology of addiction.

1. Introduction

The spectrum of addictive behaviors is wide and encompasses many dimensions of variability. Some drugs have strong hedonic effects, while others do not ${ }^{1}$. Some may involve serious, even life-threatening withdrawal symptoms, while in others these are comparatively mild. People who develop an addiction do not fit a readily recognizable pattern either, and may have

\footnotetext{
${ }^{1}$ Even though I will restrict the scope of 'addiction' to substance use for the purposes of the present discussion, the view I put forward here may be relevant to other sorts of addictions as well if there were any. As for the term 'drugs', I will use it liberally to refer to whatever substances may be the target of addictive behavior, thus including alcohol, tobacco and other substances not commonly referred to as drugs in everyday discourse. In ordinary discourse the labelling of a person as an addict often involves a negative appraisal of her behavior or her character, it is frequently meant as a stigmatizing characterization and it is often interpreted as picking out an essential trait of the agent. I wish to imply none of these things. The appropriateness of labelling addiction a 'disease' or a 'disorder' will not be part of the present discussion.
} 
originally engaged in drug use for very disparate motives. In many cases addiction can have a profoundly disruptive effect over life-projects and social relations, while in others this may be less so. There are also significant differences in the degree of severity with which a person may be addicted to some substance. As a result of all this, explanations as to why any particular individual persists in drug use will be quite diverse. And this diversity also has a reflection on the landscape of theoretical models, which variously emphasize cognitive, motivational, affective, situational, and social factors.

These observations pose a difficulty that any attempt to provide a unified picture of this multiply variable phenomenon will have to face. It is common to assume that some form of loss of control is the common underlying feature behind the many manifestations of addiction, and yet we lack a clear and viable concept of loss of control in terms of which to frame such an account. This has led some to argue that pending such understanding the claim regarding loss of control should be withheld (Sripada, forthcoming). The aim of the present paper is to put forward a clear and viable concept of loss of control that is able to fill this gap and thus provide a general framework for thinking about addictive behavior.

The development of this account involves two main steps. First, I present a view of degrees of control. Taking my cue from theories of control as reasons-responsiveness (Wallace, 1994; Fischer \& Ravizza, 1998; Nelkin, 2011; Brink \& Nelkin, 2013; McKenna, 2013; Vargas, 2013), I propose that we construe the degree of control enjoyed by an agent at a particular time as the degree to which she would be responsive to potential or counterfactual sufficient reasons to do otherwise. This graded concept of control is, I submit, able to accommodate some main differences between addicted and non-addicted agents in an intuitive way. Secondly, I sketch a pluralistic account of the relevant control-undermining factors that is consonant with my proposed view of control. Reasons-responsiveness is a very high-level functional property that may be multiply realized, and it is thus consistent with different ways in which control might be reduced. In particular, if we think of the reasonsresponsiveness that an agent displays at a particular time as a function of both the agent's psychological capacities and the opportunities her circumstances afford to exercise those capacities, then a decrease in control may result from tampering with either of these factors. On the external side, a variety of situational and long-standing environmental factors may circumscribe to different degrees the opportunities available to the agent. On the psychological side, I propose to identify a decrease in control with a feature of addicted agents' psychological processes leading to action, namely their being systematically yet defeasibly inclined to result in drug-taking outcomes. This high-level picture has the advantage 
of being consistent with various proposals as to the precise nature of the anomaly taking place in the underlying psychological mechanisms.

The plan for the paper is as follows. In the next section I will set up the questions that a theory of degrees of control in addiction needs to address, by way of discussing the problems that call for such a theory in the first place. Then in the subsequent sections I will lay out the two main parts of my account. In section 3 I will introduce some main tenets of reasonsresponsiveness theories of control, and I will discuss how such theories can make room for a graded view of control and how this can be applied specifically to account for some intuitive differences between addictive and non-addictive behaviors. And in section $4 \mathrm{I}$ will present my sketch of a pluralistic account of control-undermining factors in addiction, discussing the contribution of factors both internal and external to the agent. With the main outlines of my view in place, I will briefly discuss in section 5 some of its implications for issues concerning moral responsibility in addiction. Finally, in section 6 I will consider two possible objections.

\section{Why we need degrees of control}

The challenge posed by the variability of addictive behavior is part of what makes it so difficult to arrive at a satisfactory definition of addiction. Therapeutic approaches aim primarily at identifying the extension of the concept and providing adequate criteria for diagnosis ${ }^{2}$. We may call this the extensional problem. Note that for the purposes of diagnosis and treatment, paying due attention to variable specificity might be more important than finding a common thread that binds the pieces together. A different sort of question arises once we ask whether there is a common core to the concept of addiction that might be of theoretical significance. Or, to put it differently, whether the various kinds of behaviors that are ordinarily seen as falling under the scope of addiction really constitute a class that is in some way unified. Call this the intensional problem. It is this latter problem that will be my primary concern here.

Whether there is such a common core to the widely different types and cases might be open to question (Pickard, 2020: 9). Even though we cannot rule out a priori the possibility

\footnotetext{
${ }^{2}$ This is paradigmatically the approach of the Diagnostic and Statistical Manual of the APA (American Psychiatric Association, 2013). The DSM-V renders the "essential feature" of 'substance-use disorders' as "a cluster of cognitive, behavioral, and physiological symptoms indicating that the individual continues using the substance despite significant substance-related problems" (p. 483). As usual in the DSM, the definition is operationalized in a set of diagnostic criteria. The ten criteria provided for substance-use disorder are divided into four categories: impaired control, social impairment, risky use of the substance and pharmacological criteria. See APA (2013), pp. 483-484.
} 
that what we commonly refer to as 'addiction' could turn out to be such that no unified account is possible, that revisionary conclusion should only be seen as a last resort. In the search for common features, persistent drug use will surely come up as a key candidate, but it is not enough to distinguish addictive use from merely habitual but possibly non-addictive use. Many would argue that the definition needs to cite the presence of negative consequences of use, but this is not accepted in all quarters ${ }^{3}$. The approach I pursue in the following sections takes its cue from the thought that an agent's condition as an addict involves a peculiar type of loss of control over drug-related behavior. This peculiar loss of control, however, does not amount to a complete failure of this crucial agential capacity but is better understood as the claim that addicts enjoy a lesser degree of control over their drug-related behavior as compared to the degree of control enjoyed by non-addicts under otherwise similar circumstances. What such an account needs is a clear and viable concept of degrees of control and a view of control-undermining factors that is able to do the job that the theory of addiction requires. But before we turn to that task it will be helpful to discuss the problems that call for a view of degrees of control in the first place.

Though the idea that addicts experience a decrease in control is not new, it is far from universally accepted. Much of the work on this issue has tended to cluster around two main families of views. Compulsion views see addiction as involving a substantial impairment in addicts' control when it comes to drug-related behavior ${ }^{4}$. On these views, drug-taking is not something addicts choose to do in any significant sense, but something they are drawn to in a compulsive way. Choice views, on the contrary, emphasize the sense in which addictive

\footnotetext{
${ }^{3}$ Besides the already quoted definition in the DSM-V, other definitions that make a reference to negative or harmful consequences include World Health Organization (2014); National Institute on Drug Abuse (2014); Heather (1998); Sinnott-Armstrong \& Pickard (2013). A dissenting voice is found in Watson (1999: 13).

${ }^{4}$ Loewenstein (1999) and Levy (2010) may be cited as examples of a view of this kind. It is also frequently the assumed view of addiction in the literature on free will and moral responsibility. Frankfurt (1971) and Watson (1977) come to mind as two paradigmatic examples.

Compulsion views are also widely held in the medical and mind sciences, with a plausible claim to being the mainstream view of addiction in those fields. The reference to "compulsive drug-taking" is incorporated in the DSM-V's characterization of severe substance-use disorder (APA 2013, p. 485), which is colloquially identified as addiction. It is also the view of addiction held by the National Institute for Drug Addiction (NIDA), which defines addiction as "a chronic, relapsing brain disease that is characterized by compulsive drug seeking and use" (NIDA 2014, p. 5). Though the claim regarding compulsion is widely held and has a long history, it has of late been particularly associated with the 'Brain Disease' model of addiction (Kalivas \& Volkow, 2005; Volkow, Koob, \& McLellan, 2016). A concern may arise, however, regarding what exactly is meant by compulsion-talk in the medical literature, where this is typically left underspecified.
} 
behavior may be seen as a chosen means to a desired end $\mathrm{d}^{5}$. These latter views usually cite some factor other than loss of control to explain why addicts persistently choose the way they do. Though both kinds of views may be said to contain a grain of truth, I think that ultimately the focus on the Compulsion/Choice dichotomy is misguided and that intermediate theoretical alternatives may prove more fruitful ${ }^{6}$.

For the meantime, however, Compulsion and Choice views represent useful reference points in terms of which to frame the idea of a decrease in control. I will proceed by contrasting the decreased control claim with two admittedly extreme versions of its alternatives in logical space, which I will call the Pure Compulsion and the Pure Choice views. As I will be using these terms, the core tenet of the Pure Compulsion view is that addicts face a condition of total absence of control and the corresponding core tenet of the Pure Choice view is that addicts retain full, unimpeded control over their drug-related behavior ${ }^{7}$. Upon scrutiny, both the Pure Compulsion and the Pure Choice views turn out to be highly implausible and unappealing.

Let us focus first on some issues a Pure Compulsion view would have to face. Consider, as a first pass, that many addicts describe their behavior as voluntarily chosen. It is true that

\footnotetext{
${ }^{5}$ See Gene Heyman (2009). Some statements by Hanna Pickard (2012; 2017; 2018; 2020) suggest a view along these lines, though in other passages she acknowledges that control may be compromised in addiction to some extent. Some versions of Self-Medication (Khantzian, 2003) and of Learning models of addiction (Lewis, 2017) also have affinities with this kind of view.

${ }^{6} \mathrm{I}$ am not the first to argue that we should move past the Compulsion/Choice dichotomy and look for intermediate alternatives. Others include Wallace (1999); Watson (1999); Holton (2009); Holton \& Berridge (2013); Flanagan (2013); Sinnott-Armstrong (2013); Sinnott-Armstrong \& Pickard (2013); Henden (2018).

${ }^{7}$ As noted in the text, 'Pure' Compulsion and 'Pure' Choice views are meant as theoretical poles, serving as reference points to present the concept of a decrease in control. However, proponents of both Compulsion and Choice views do appear at times to approximate these more extreme variations of their positions. For instance, Carl Elliot depicts the addict as someone who "must go where her addiction leads her, because the addiction holds the leash" (2002: 48); and Louis Charland describes the condition of someone diagnosed with drug (heroin) dependence as someone whose "decisions that relate directly to heroin use are susceptible to powerful physiological and psychological compulsions that usually nullify any semblance of voluntary choice" (2002: 41; emphasis added); and Nora Volkow speaks of addiction as a condition under which "a person's brain is no longer able to produce something needed for our functioning and that healthy people take for granted, free will' (from her blog post 'Addiction is a Disease of Free Will', based on her inaugural address as Director of the National Institute on Drug Abuse, retrieved from: https://archives.drugabuse.gov/about-nida/noras-blog/2015/06/addictiondisease-free-will on march 4th 2021). Proponents of Choice views also occasionally state their claims in ways that suggest more extreme views than the authors' own considered judgements would allow. For instance, Hanna Pickard at times articulates her view by saying that "addicts use drugs and alcohol purposively (...). Consumption is a chosen means to desired ends. If the ends are no longer as pressing, or alternative ways of achieving them are available, it is possible to choose differently" (2012: 41) and that "drug choice in addiction is voluntary and value-based" (2020: 8). As noted before, however, in other passages Pickard gives a more nuanced statement of her view, acknowledging that control may be compromised in addiction to some extent.
} 
anecdotal first-person reports are tricky, and their evidential status might be contested. And it is also true that first-person reports by other addicts may be cited in support of the existence of a loss of control phenomenon ${ }^{8}$. However, reports of addictive behavior as voluntarily chosen pose an initial challenge to the Pure Compulsion view. (As it happens, first-person reports by addicts also challenge the Pure Choice view, and their conflicting nature is arguably more easily accommodated by the decreased control claim, which sees control as partially compromised and at the same time partially retained).

A potentially trickier issue for a Pure Compulsion view to deal with is the threatening emergence of what we may call a 'puzzle of recovery'. If appropriate stimulus conditions trigger particular actions that the agent has no capacity to prevent, then dependence might be accounted for at the cost of making it seem puzzling how someone might have a potential for recovery from active, regular substance use. And it seems that at least some addicted individuals exhibit the ability to quit active regular use in the long term. The Pure Compulsion view thus faces a challenge to explain how is that possible 9

More importantly, there is direct evidence that suggests that addicts retain at least a certain degree of control over their drug-related behavior. Consider the familiar fact that even people who are severely addicted are often able to regulate circumstances of use and may successfully exercise the ability to refrain from using over shorter periods of time -even heavy smokers are often successful at refraining from smoking during airplane flights. It is natural to assume that there would be no explanation for that ability without the agent retaining some degree of control over her drug-related behavior. And the experimental evidence also points in the same direction. It has been shown, for instance, that under forced-choice conditions addicts may prefer monetary rewards over drugs (Hart, Haney, Foltin, \& Fischman, 2000). The same principle is operative behind contingency management treatments, which offer rewards to abstaining patients (Petry, Alessi, Olmstead, Rash, \& Zajac, 2017). In some cases, addicts may even choose to go through withdrawal in order to amplify the effect of future use and thus reduce their drug expenses (Ainslie, 2000: 82), which also suggests a much greater degree

\footnotetext{
${ }^{8}$ For both kinds of first-person reports from addicts, see Hänninen \& Koski-Jännes (1999). Another interesting source of first-person stories of addiction is the Crackdown podcast, available at https://crackdownpod.com/.

${ }^{9}$ Of course, this observation falls short of an argument that such a challenge cannot be met. For instance, a Pure Compulsion theorist could claim that formerly compulsive, irresistible desires lose that quality and become resistible during the process of recovery. Or she could argue that people who are able to recover were not true addicts to begin with or not the kind of addicts that the account is meant to apply to. For present purposes, it suffices to note that a Pure Compulsion view would be required to come up with a convincing reply to the puzzle of recovery.
} 
of flexibility than a Pure Compulsion view is able to make room for. Further, statistical surveys have shown that a great number of people who suffer from addiction in their twenties are able to overcome that condition without any sort of treatment as they grow older. Though the data might be accounted for in a number of ways, it has sometimes been interpreted as providing presumptive evidence against a view of addictive behavior as purely compulsive (Heyman, $2009)^{10}$.

Let us see then what are the prospects of a Pure Choice view. It is entirely plausible that part of the explanation for addicts' persistent drug-use may sometimes involve relevant features of the agent's circumstances. Consider, for instance, the cases of people who resort to drug-taking because they suffer from chronic pain or from persistent psychological distress due to some other condition (Khantzian, 2003; Kessler, Chiu, Demler, \& Walters, 2005), or of homeless people who have in the short term no realistic prospect other than living in the streets (Kennett, 2013). Further, when contrasted with a Pure Compulsion model, a Pure Choice view has the advantage of bringing into the picture the way in which addicts' beliefs and desires play a role in their decision-making. Nevertheless, construed as the claim that addicts retain full control over their drug-related behavior, a Pure Choice view is surely incorrect.

A first source of concern arises once we take a closer look at the implications of the full control claim. In a nutshell, the worry stems from the thought that being pressed by situational factors to take a certain course of action may effectively amount to being deprived of a relevant dimension of control, which we may call situational control (Brink \& Nelkin, 2013). In extreme cases this may result in a substantial loss of control, with duress as a paradigmatic example. But even circumstances that afford some leeway to the agent may in some cases result in a significant decrease in control if they are sufficiently pressing ${ }^{11}$.

Further, the familiar fact that addictions can be so difficult to quit seems to go plainly against the claim that addicts retain full control over their drug-related behavior. Indeed, many addicts struggle to overcome their habit even when painfully aware that it is bringing great harm to themselves or the people around them. Some of these agents may find themselves in

\footnotetext{
${ }^{10}$ As the text implies, that interpretation may be open to dispute. Sinnott-Armstrong (2013: 132-133) discusses possible grounds for scepticism about Heyman's interpretation.

${ }^{11}$ Another way to frame this worry is in terms of the distinction between a general and a specific sense of ability (Whittle, 2010; Clarke, 2009). That is, when we wonder how much control an addicted agent enjoys over her drug-related behavior we are not asking whether she retains the general ability to control her behavior but whether she is presently able to exercise that ability in the actual circumstances she finds herself in.
} 
circumstances that afford no preferable alternative to continuing drug use, but there are many others who could benefit from available opportunities and still experience a decrease in control over the relevant behaviors. It is telling in that regard to think of the lengths some people go to in their effort to shake off their addiction, spending significant sums of time and resources looking for treatment opportunities. Some addicts tend to the use of medications that will cause them to get sick if they indulge in drug use, and some fail to refrain from using even while knowing that it will result in guaranteed sickness (Sripada, 2018: 572). Even if we find some plausibility in the idea that cigarette smoking is a chosen means for coping with stress or anxiety, it is challenging not to invoke a certain degree of loss of control to explain why some people (arguably, a small subset of smokers) may feel tempted to temper with smoke detectors in airplane restrooms.

Considered together, the preceding arguments suggest that addictive behavior retains a certain degree of flexibility, and -at the same time - that such flexibility is importantly limited in a number of ways. On that account, a view of addiction involving a decrease in control that does not amount to an obliteration of this crucial agential capacity fares better than either a Pure Compulsion or a Pure Choice view. What we need in order to develop such account is, first, a clear concept of control that enables us to make sense of it as something that may come in degrees, and secondly, we need to put that concept to work to understand how the relevant decrease in control may come about in addiction. I turn to these tasks in the following sections.

3. A reasons-responsiveness account of degrees of control

The concept of control plays an important role in the literature on addiction, as it is commonly claimed that some form of loss of control is an essential component of the explanation of addictive behavior. Despite this being a common view, it is far from clear how the relevant concept of control should be understood and what exactly is meant by 'loss of control'. The lack of a clear concept has even led some to argue that pending such understanding the claim about loss of control should be withheld (Sripada, forthcoming).

Besides discussions of addiction, the concept of control has also played a prominent role in the literature on free will and moral responsibility. In this context, it has been taken to mean different things. A person may be said to be in control of what she is doing if it is up to her on which possible course of action she will settle. Or it may be thought that in order to enjoy control over her actions a person needs to have the capacity to do otherwise than what she is 
actually doing. Both ideas ring true when applied to the distinction between addictive and non-addictive behavior, but they themselves involve the difficult and highly contested notions of 'up-to-oneness' and 'being able to do otherwise' (Clarke, 2020). Moreover, it has often been questioned whether any of us enjoys control under some readings of these concepts.

A different and, for present purposes, better suited idea is that for an agent to have control over her actions at a particular time amounts to her behaving in a way that reflects an appropriate sensitivity or responsiveness to reasons (Wallace, 1994; Fischer \& Ravizza, 1998; Nelkin, 2011; Brink \& Nelkin, 2013; McKenna, 2013; Vargas, 2013). To a first approximation, this means that were sufficient reasons to do otherwise to present themselves (given a relevantly similar context), the agent would adjust her behavior accordingly. Conversely, an agent acting in a purely compulsive way, enjoying no control over her actions, would not behave differently even if presented with sufficient reasons to do so ${ }^{12}$. This general sort of approach allows us to frame the issues concerning addiction in terms of a relatively clear concept, without involving potentially troublesome metaphysical assumptions and allowing for the possibility of making sense of control as something that a person may enjoy to different degrees under different circumstances.

Fischer and Ravizza (1998) distinguish between weak, moderate, and strong forms of reasons-responsiveness. On their account, we get strong reasons-responsiveness when the agent is acting on a mechanism that behaves differently in the closest possible world in which (given a relevantly similar context) there is sufficient reason to do $\mathrm{so}^{13}$. By contrast, it suffices for weak reasons-responsiveness that the agent behaves differently at least in some possible world in which (given a relevantly similar context) there is sufficient reason to do so. Their

\footnotetext{
${ }^{12}$ This view is meant to be compatible with a fairly deflationary account of reasons and need not entail any particular ontological commitments in this regard. It is not implied either that the capacities underlying reasons-responsiveness do not involve an affective dimension. Further, following Fischer and Ravizza's account (1998: 77), what constitutes a sufficient reason to do otherwise may be deferred to the considered judgements in wide reflective equilibrium of the relevant community. Finally, a stipulation should be added to the effect that the agent's reaction to the presence of the relevant reasons be appropriately connected to her appreciation of what those reasons are.

${ }^{13}$ Fischer and Ravizza's (1998) account of reasons-responsiveness construes it as a property of the 'mechanism' or the set of sub-personal processes that lead to action rather than as a personal-level property of agents. Other reasons-responsiveness theories (e.g., Nelkin, 2011; Brink \& Nelkin 2013; McKenna, 2013; Vargas, 2013) opt instead for an agent-based approach. The decision to favor one sort of approach over the other turns on some potentially tricky issues, including different ways of responding to Frankfurt-type scenarios and the difficulties involved in providing an account of mechanism individuation (for discussion, see McKenna, 2013). For present purposes, I shall remain neutral between these different ways of specifying the reasons-responsiveness account. Even if, for ease of exposition, I refrain from explicitly re-stating both possibilities with each reference to reasonsresponsiveness, I intend to be interpreted in terms of this neutral stance.
} 
intermediate concept, moderate reasons-responsiveness, obtains when the agent is acting on a mechanism that is regularly receptive and weakly reactive to reasons ${ }^{14}$.

This distinction between weak, moderate, and strong reasons-responsiveness is meant to set thresholds for different degrees of control. But it provides the basic blueprint in terms of which a fully scalar notion of control might be developed. In a rough approximation, the degree of reasons-responsiveness that an agent displays is a function of the range of sufficient reasons to do otherwise she would be responsive to. Or, to put it differently, it is a function of the range of possible worlds in which (given a relevantly similar context) sufficient reasons to do otherwise present themselves and the agent successfully responds to them. In particular, the control that an agent enjoys over her actions at a particular time would be diminished if the range of possible worlds in which she successfully responds to sufficient reasons to do otherwise (given a relevantly similar context) were to be suitably restricted.

There are different ways in which an approach along these lines may be more fully worked out. Degrees of control may be taken to correspond to the suitable proportions of possible worlds in which the agent finds herself in a context relevantly similar to the target context in the actual scenario and responds accordingly to sufficient reasons to do otherwise (Vargas, 2013). Or they might be equated with degrees of comparative similarity between the actual world and the nearest possible world in which the agent responds to sufficient reasons to do otherwise (Coates \& Swenson, 2013). Thus, the degree of control that the agent enjoys might be defined in terms of how distant from the actual world we need to go in similarity space to get the agent to respond to sufficient reasons to do otherwise. Each of these possibilities is as presented still importantly underspecified, as some issues would still need to be worked out concerning how to measure and compare proportions of possible worlds or degrees of similarity, which possible worlds would constitute appropriate bases of comparison and some further issues involved in the fine tuning of the counterfactual machinery. For present purposes, however, a rough approximation to the idea of degrees of reasonsresponsiveness suffices to get a grip on how it can illuminate our thinking about addiction and other control-undermining phenomena.

\footnotetext{
${ }^{14}$ Fischer and Ravizza impose asymmetrical requirements on receptivity and reactivity as a result of their claim that "reactivity is all of a piece" (1998: 73). 'Regular' receptivity is meant to exclude patterns of response that would look haphazard or strange by the lights of a third party. Thus, it reflects the requirement that there be an appropriate connection between the relevant reasons and the agent's responses.
} 
Suppose that Mark and John both decide to drink beer on a particular night, and they both end up getting drunk. And suppose further that Mark is an occasional drinker and John suffers from severe alcoholism. Even if their behavior on that particular night was indistinguishable from the perspective of an outside observer, we still feel that there is a difference in how their actions came about. A useful way to capture that difference is in terms of how they would have responded in various counterfactual scenarios in which a sufficient reason to refrain from drinking that particular night had presented itself.

This counterfactual test plausibly yields two important results for our purposes. First and contrary to what a Pure Compulsion view would hold-, in all likelihood both Mark and John would refrain from drinking under some conceivable scenarios. Suppose, for instance, that they came to believe that just one more bottle of beer would result in their immediate death, or that an $\mathrm{H}$-bomb would wipe out a neighboring town if they took up their glasses one more time. Of course, we would say that John only enjoys the weakest possible sense of control if those were the only scenarios in which he would refrain. But even if that were the case, his pattern of response would be inconsistent with the claim that his drinking behavior is literally and totally out of his control. The second conclusion that the counterfactual test plausibly invites is that, holding other variables fixed, the set of possible scenarios in which Mark would respond to sufficient reasons to refrain from drinking that night would be much larger than the corresponding set for John.

Some clarifications are in order. An agent's capacity for reasons-responsiveness may be factored into a cognitive and a volitional component. In order to behave in a reasonsresponsive way an agent needs to have the requisite understanding of considerations pertaining to her course of action, and that understanding needs to have the requisite impact on her behavior. In Fischer and Ravizza's terms, the agent must be both receptive and reactive to the relevant reasons. If either of these components were to fail, we would not consider the agent's behavior as properly under her control in the relevant sense. This feature of reasonsresponsiveness is something we want from an account of decrease in control in addiction, as it will help us deal with addiction's wide scope of variability. For instance, in many cases addicts have a clear understanding of their condition and are receptive to reasons to refrain from engaging in the relevant behaviors, and yet fail to show the requisite levels of reactivity. This is surely an important kind of case, and the condition of many addicts may be described in those terms. Many smokers, for instance, acknowledge that smoking results in significant health problems, and even grant that it would be advisable for them to quit given their desire to live long and healthy lives, and yet fail to follow through with actions appropriate to that 
judgement. However, not all cases will be like that, and the distinction between receptivity and reactivity gives us room to deal with other ways in which an agent may fail to be responsive to reasons. Another important sort of case is probably better described as involving a failure of receptivity, as the condition of some addicts involves denial about the consequences of their behavior or significant biasing of their judgement when it comes to issues related to their addiction. It is therefore a positive feature of an account of decrease in control that it is able to capture these different kinds of cases under the broader notion of reasons-responsiveness, while at the same time providing the resources we need to think about the specificity of particular cases as involving either failures of receptivity, of reactivity or both.

Another important caveat is that control is not a fixed or stable property of agents, but one that might be highly variable across different times and circumstances. This follows naturally once we think of control as the capacity to respond to sufficient reasons to do otherwise, given that the cognitive and volitional components of that capacity may be affected by several factors both internal and external to the agent. For instance, the agent's degree of maturity is surely one such factor. A young person maturing through adolescence gains higher degrees of control over her actions as her capacities for understanding and for volitional control develop, and this is reflected in our judgements concerning degrees of responsibility for maturing agents (Coates \& Swenson, 2013). But many other factors may affect an agent's degree of responsiveness without involving diachronic change. All of us are more competent at tracking relevant considerations in some domains than in others (Vargas, 2020). And even holding fixed the agent's internal features, relevant differences in context and circumstance may equally yield important differences in the agent's capacity to control her behavior. For instance, some cases of peer pressure may diminish an agent's responsiveness to reasons to refrain from drinking at a particular situation, as I discuss in more detail below. Conversely, fear of being judged or frowned upon by onlookers may in some cases have the effect of enhancing an agent's capacity to refrain from acting on certain impulses.

This allows us to bring into clearer focus the earlier claim that an addicted agent's condition involves a lesser degree of control over drug-related behavior as compared to the degree of control enjoyed by non-addicted agents under otherwise similar circumstances. At the outset it should be noted that the claim is indexed to drug-related behaviors, as it would likely be incorrect to assume that addicts display a perfectly generalized failure of control ${ }^{15}$.

\footnotetext{
${ }^{15}$ I do not mean to imply that there are no other regards in which the decision-making processes of addicted agents may be somehow anomalous (Verdejo-Garcia, 2018). Whether this is the case, what
} 
And the comparative element involved in the reference to non-addicted agents should be interpreted in the light of the foregoing clarifications. In particular, it should not be taken to imply that the degree of control enjoyed by non-addicts will be equivalent for all agents or even for the same agent at different times or under different circumstances.

The present account affords an elegant way to capture the difference between addiction and behaviors that are simply habitual or that result from strong motivation. We all tend to develop habits and routines, which are a prominent feature of human psychology. Importantly, habits and routines once settled may be hard to change. Say that Martha goes through the same routine every morning after waking up, eats the same things for breakfast and goes through the same steps while preparing it. It may even be true in some colloquial sense that she 'needs' to go through those steps in order to start the day in a good mood, and she might be somewhat put off if something interferes with her routine. Still, it is easy to feel the force of the intuition that there is a sufficiently wide range of potential or counterfactual reasons in the presence of which she would behave differently. What that intuition is pointing to is the sense in which a person may have a deeply settled habit but still enjoy a considerable amount of control over her behavior.

The same may be said regarding behavior that results from high levels of motivation. Say that Maia is highly committed to her medical training, spends long hours studying and is not easily distracted by other pursuits. Still, insofar as we construe her as being in control of her conduct, it seems intuitively correct to claim that there is a sufficiently wide range of potential considerations that she would be responsive to and in the light of which she would behave differently. The picture looks importantly different for addicted agents, for whom the corresponding set of potential or counterfactual reasons to refrain from using they would be responsive to is plausibly much narrower.

Another feature of this account is that it allows for a simple way of capturing differences in degree between different points in the spectrum of drug abuse. As we noted at the outset, the phenomenon of addiction involves a great deal of variability between importantly different sorts of cases. One such dimension of variability concerns the severity of the condition a person may be subject to. For instance, the DSM-V distinguishes between 'mild', 'moderate' and 'severe' forms of substance-use disorder. While the term 'addiction' is not used as a diagnostic term in the manual, it is observed that it is frequently used by clinicians to refer to

kinds of processes are compromised and to what extent, are all questions to be settled in the light of appropriate evidence. 
its severest forms (APA, 2013: 485) ${ }^{16}$. Degrees of severity for addiction may be usefully thought of in terms of degrees of reasons-responsiveness along the lines proposed here.

4. A pluralistic account of control-undermining factors

A further advantage of a reasons-responsiveness view of control is that it is consistent with a range of different explanations regarding how control might be lost or diminished. Of crucial importance here is that there is no need to assume that factors internal to the agent are the only relevant ones to determine the degree of control an agent enjoys at a particular time. On the contrary, the degree of reasons-responsiveness that an agent enjoys at any particular time will be a function of both her psychological dispositions and capacities at that time and a set of varying situational or long-standing environmental factors that may facilitate or circumscribe the opportunities available for the exercise of her capacities (Brink \& Nelkin, 2013).

That different kinds of situational factors may diminish an agent's control over her drugrelated behavior should come as no surprise. As noted earlier, some forms of peer pressure may be one such control-diminishing factor. In some cases, the expressed opinions of others may provide the agent additional reasons to pursue certain course of action, without compelling her in any relevant sense. Yet some forms of peer pressure may be function at times as something more akin to duress, resulting in offers that the agent effectively 'cannot refuse' or artificially imposing high costs for the agent if she does not fall into line. Under those circumstances, some of the available and otherwise reasonable options cease to be live possibilities for the agent. In those cases, peer pressure may restrict the agent's capacity to respond to the relevant reasons and thus, in an important sense, effectively diminish the agent's control over her behavior.

Other environmental variables may also restrict the agent's reasons-responsiveness in other ways. For instance, finding herself in certain kinds of settings - e.g., settings that bear a learnt association with drug use - may have an influence over the agent's relevant capacities that effectively results in her enjoying a lesser degree of control in those contexts. Part of the

\footnotetext{
${ }^{16}$ In accordance with the way the DSM works, the different degrees of severity are equated with the presence of different quantities of the relevant symptoms -2 or 3 for the mild, 4 or 5 for the moderate and 6 or more for the severe. Thus, the DSM points to a gradient of differences of a scalar nature, even though this is not captured in a very precise way by the characteristic quantity-of-symptoms approach of the manual. Nevertheless, insofar as the DSM implies that there is a need to think of addiction as something that someone may suffer to different degrees, the present account in terms of degrees of reasons-responsiveness provides a tool for thinking about degrees of severity that could be useful in practice.
} 
explanation for this presumably lies in the fact that both the rate and the intensity with which an addict experiences craving for drugs are affected by the presence of environmental cues (Skinner \& Aubin, 2010). That is why many people struggling to recover from an addiction seek to improve their self-control by distancing themselves from environments and social relations that they have come to associate with drug-taking. In Al Mele's (1990) terms, they thus seek to improve their self-control by circumventing their desires. A related strategy to enhance selfcontrol is to seek support and positive reinforcement from groups of recovering addicts which afford new forms of community membership and identity, together with peer pressure to remain abstinent (Flanagan, 2013).

Conversely, opportunities denied may make it harder for someone to achieve selfcontrol. If an important step in the struggle to overcome addiction is to attain new forms of community membership and social identity (Flanagan, 2013, 2018; Pickard, 2020), then restricted opportunities to achieve either of these things may in some cases effectively result in a decrease of the agent's control over her drug-related behavior. It is telling in this regard that addiction is statistically correlated with limited socio-economic opportunities (Pickard, 2018: 15). The correlation could be interpreted in several ways, but it seems plausible to infer that the degree of control that an agent enjoys over her drug-related behavior may be restricted to some extent under conditions that narrow the available opportunities for pursuing alternative life-trajectories (Hart, 2013) ${ }^{17}$.

All this notwithstanding, any theory of addiction that focuses solely on external factors would be incomplete. Indeed, most current theoretical models of addiction posit some sort of psychological anomaly as part of the explanation of addictive behavior ${ }^{18}$. This is another regard in which a reasons-responsiveness approach to degrees of control affords a valuable

\footnotetext{
${ }^{17}$ As noted before, the rationale for this is that under the present account control is understood in terms of the exercise of certain rational and volitional capacities. If the premise is granted that situational and environmental factors of the kind cited here may in some cases have an impact over the agent's relevant capacities, then that amounts to their having an impact over the agent's control. The key thought is that the opportunities that the present situation affords to the agent are an integral part of the explanation of what the agent is presently able or not able to do. A full discussion of this point, however, would lead to some tricky issues concerning the interpretation of capacity-talk that are beyond the scope of this paper. For discussion of the relevant notion of capacity, see Clarke (2009) and Vargas (2013), chapter 7.

${ }^{18}$ By 'anomaly' I mean simply that there is something in the way these processes are working that is peculiar or distinctive. Moreover, it is something that makes it the case that there is a difference between how these processes are working in addiction and how they ordinarily work, both for nonaddicted agents and possibly for addicted agents too when it comes to matters not related to drug use. As I mentioned before (note 1), I remain neutral on the issue of whether it is appropriate to label addiction a 'disease' or a 'disorder', as this raises further questions about the concept of a disease that are beyond the scope of this essay.
} 
opportunity to bring under a unified picture different available explanations as to the precise nature of the anomaly involved. I propose to do so in terms of a view of decision-making processes in addiction as systematically yet defeasibly inclined to result in drug-using outcomes.

First, let me clarify and qualify what I meant by 'decision-making processes'. Simply put, what I will be referring to in what follows is the process through which an agent settles in a particular course of action, in a way that is by definition stipulated to be causally efficient in the production of that action. In other words, I do not mean to pick out a process of practical deliberation that may or may not find its way into action, but the actual process that ensues in the agent acting in the way that she does. This process may take place explicitly and with full awareness, e.g., weighing pros and cons for a particular course of action, or it might take place in a less reflectively loaded manner. Further, it may be thought of as a one-layer process or as a more complex hierarchical or parallel set of processes. For present purposes, I will remain neutral on these and other important issues regarding how people settle on a particular course of action and execute it. As my aim here is just to pick out the process from which action ensues, regardless of how we think about the details of the way in which the process is carried out, in what follows I will refer simply to the concept of an 'action-ensuing process'.

The inputs to such process will typically involve several occurrent and dispositional psychological states. Among these are ordinary desires and also what George Loewenstein called 'visceral factors' (Loewenstein, 1996; 1999; Elster, 1999), encompassing the different kinds of affective states and bodily-centered drives and urges such as hunger, thirst, sexual desire, the urge to sleep, among others, together with feelings arising from bodily disturbances such as pain, fatigue and nausea, among others. Besides the prominent way in which they feature the body, a salient common trait of visceral states is the force with which they influence action-ensuing processes, what we may call their motivational salience (Holton \& Berridge, 2013). These are, however, not the only inputs to these processes, and we need not assume that they constitute the only source of motivational strength. Among the further factors that would need to be part of a complete story of action-ensuing processes are the agent's beliefs and other cognitive states, her evaluative judgements, and probably her longstanding goals and policies as well, among other factors.

There are at least two mistakes that an account of the anomaly involved in the psychology of addiction should aim to avoid. First, as we discussed earlier, it should be consistent with the agent retaining a certain degree of control. Secondly, even if addicts 
experience a decrease in their capacity to control their drug-related behavior, and so have their capacity to do otherwise reduced to a certain extent, it would be difficult to make sense of the idea that their wanting to take the drug is not part of the explanation of their behavior. Some addicts may continue to want to use their drug of choice even when they no longer like it or get as much pleasure from it (Robinson \& Berridge, 1993; 2008). But it seems correct to assume that an adequate account of addictive behavior would need to feature the addicted agent's desires or 'wantings' for the drug as playing a role in her action-ensuing processes, together with her beliefs and other relevant occurrent and dispositional psychological states.

With those desiderata in mind, consider the following analogy inspired by one proposed - with a different purpose in mind - by Randy Clarke (1994: 5). Imagine there is a ping-pong ball rolling through a smooth plane. Imagine further that the movement of the ball is subjected to the influence of air currents coming from different sources, pushing the ball in different directions. If we picture the air currents as the different factors driving the action-ensuing process, we may think of the way the process can be systematically yet defeasibly inclined towards one particular outcome as a slight tilting of the surface over which the ball is moving. The inclination of the plane would need to be significant enough to account for the ceteris paribus increased likelihood of the ball going in that direction, but still not steep enough as to make it impossible for other forces to pull the ball in a different course.

A picture of this general sort conveniently captures some of the main features that are required of the account we are aiming for. First, it allows for a way of thinking about how there might be a systematic anomaly in the action-ensuing process without the implication that the agent is not making decisions after all, or that her desires and value judgements are inefficacious. Under the picture just presented, the agent is making decisions and is exercising rational and volitional capacities, only the way those capacities are functioning is tilted towards a particular outcome. This incline, moreover, is not steep enough as to completely dictate the course the agent will follow. Or, to put it differently, it does not lead to a total disruption of the agent's rational and volitional capacities. In this way, the incline of the actionensuing process, though defeasible, is enough to explain how the agent's behavior is less responsive to reasons than it would otherwise be if the process were not thus inclined. What this affords, then, is a picture of the agent's control as being diminished and, at the same time, partially retained.

The concept of an action-ensuing process that is systematically yet defeasibly inclined to drug-taking outcomes affords a way of thinking about the anomaly taking place in the agent's 
capacities that is still at a fairly high level of description and, consequently, that would need to be cashed out in more concrete terms. There are in principle many ways in which such highlevel profile may be instantiated, and I take that level of generality to be a positive feature of a framework for thinking about decreased control in addiction. As I stressed at the outset, addiction is a highly variable phenomenon, and it is likely that there is no unique way to explain the tiltedness of the action-ensuing process that will be applicable to all types and cases. In that sense, to tie the account to one specific story about what is doing the tilting would likely undermine its scope of application. A pluralistic account of the psychological mechanisms involved seems a sounder strategy ${ }^{19}$.

Let us see some main ways in which the high-level property of tiltedness may be instantiated. One way would be to bestow a prominent role to cravings, as the intense and recurrent desires for drug-taking that addicts experience. An appeal to cravings seems a promising move as they are a key phenomenological feature of addiction, are present in a very wide range of cases and are a of course an important source of motivation for drug-use. There are at least two main ways in which a craving-based account can be developed: in terms of their heightened intensity (Holton \& Berridge, 2013) or in terms of their recurrent nature (Sripada, 2018). The former would be a revised way of capturing the intuition behind the traditional concept of 'irresistible desires'. While not literally 'irresistible', cravings may gain enough motivational salience as to constitute a powerful force driving the action-ensuing process, thus making it harder for other factors to counterbalance their motivational force.

The latter route to a craving-based account would highlight instead the recurrent nature of craving episodes that addicted agents experience. Cravings for drugs may be triggered by the presence of drug-related cues but they may also occur spontaneously. And they may be felt several times a day and present an intrusive character, inviting a comparison with the role of obsessive thoughts in obsessive-compulsive disorder (Anton, 2000). This is another way in which the overall process may be inclined to drug-taking outcomes, as the recurrent engagement of self-regulatory mechanisms brings significantly high costs for the agent,

\footnotetext{
${ }^{19}$ The pluralistic stance regarding the precise nature of the psychological underpinnings of tiltedness may give a reason to prefer a mechanism-based over an agent-based account of reasons-responsiveness (see note 13 above). The concept of a 'mechanism' is not easily defined and gives rise to some difficult questions regarding mechanisms' individuation and demarcation. Still, it is probably safe to assume that different mechanisms are involved in the production of action. Moreover, it is likely as well that the anomaly that results in the overall tiltedness of the process leading to action may be traced back to the operation of different mechanisms in different cases. That sort of picture would also be able to explain elegantly why the same agent may appear to be differently responsive to reasons in different occasions. I thank an anonymous referee for pointing out this possibility.
} 
ranging from the hedonic cost involved in the aversive phenomenology that often accompanies mental effort, to the opportunity cost of recurrently deploying mechanisms that become thus temporarily unavailable to fulfill other tasks (Sripada, forthcoming; Kurzban, Duckworth, Kable, \& Myers, 2013). Thus, both the intensity and the recurrence of felt urges to use drugs may result in a systematically tilted action-ensuing process. A craving-based account may combine both features.

Even if it is highly plausible that there is something right to craving-based accounts, there is no need to assume that they will be able to explain all forms of addiction, or even that they will be the sole correct explanation of what is taking place in the cases where they do apply. Tiltedness may also be instantiated by the way that cognitive elements involved in the action-ensuing process are operating. For instance, drug-related cues and considerations may acquire in addiction a heightened pull on attentional focus, thus taking up a significant proportion of available attentional resources (Henden, 2018). If we assume that the allocation of attentional resources can influence the action-ensuing process (making it, for instance, harder to bear in mind available reasons not to take the drug) and given the finite nature of attention and working memory resources, this may be another systematic factor inclining the overall process towards drug-taking outcomes, without the implication that this outcome is thus rendered inevitable.

Another interesting possibility is that drug-related beliefs and value-judgements could be functioning in addiction in an anomalous way, being prone to regular and uncontrollable shifts (Levy, 2014; 2018). According to this account, a main reason why it is so difficult for addicts to remain abstinent is that their all-things-considered judgements concerning what they have most reason to do prove remarkably unstable, being regularly susceptible to shifts that may nevertheless fail to express the agent's settled preferences. This is yet another way in which decreased reasons-responsiveness may be instantiated. Under the belief-oscillation hypothesis, the agent's all-things-considered judgements shift in some critical moments, but they do not do so in response to a renewed appreciation of actual sufficient reasons to behave differently. At the moment the agent changes her all-things-considered judgement, the reasons available to her are much the same as before, only she fails to reach the same conclusion. What is driving the shift, under this picture, is not itself a consideration of those reasons but some sort of anomaly in the mechanism responsible for belief formation.

A related and often cited idea is that many addicts suffer from a sort of temporal myopia when it comes to estimating the value of future rewards. In particular, addicts may 
systematically overestimate the utility of immediate rewards and underestimate the utility of future rewards as the length of the delay increases. All of us do this to a certain extent, but there is evidence that addicted individuals do it to a much larger extent than non-addicts (Bickel, Koffarnus, Moody, \& Wilson, 2014). The time expected to elapse before getting a reward is, as economists acknowledge, a rational consideration to weigh in a decision process. However, to discount the value of future rewards 'hyperbolically' as some addicts do, assigning too much value to immediate rewards and failing to value long-term utility, is another way in which an agent may fail to be receptive to sufficient reasons to behave differently. In cases exhibiting this kind of temporal myopia, the changes in the value assigned to future rewards are not tracking relevant reasons to behave in one way or another but are signs of an anomaly in the way in which the expected value of future rewards is calculated by the agent. Thus, both belief-oscillation and hyperbolic discounting of future rewards constitute cognitive routes to a systematically tilted action-ensuing process without resulting in a complete loss of control on the part of the agent ${ }^{20}$.

This quick tour of some main available explanatory strategies is not meant of course to exhaust the landscape of theoretical options. But it gives us a firmer grip on the way control may be diminished in addiction, as it affords a clearer picture of some ways in which the systematic tiltedness of the action-ensuing process may be variously instantiated. Note that although these various models are often depicted as conflicting with one another, under the picture proposed here they amount to different ways of instantiating a common high-level profile. A pluralistic stance on control-undermining factors is more likely to be successful given the many dimensions of variability involved in addiction.

Where does this leave us, then? As we discussed earlier, to construe degrees of control as degrees of reasons-responsiveness allows for an intuitive way of thinking about the

\footnotetext{
${ }^{20}$ Another way to frame what is anomalous in cases of belief-oscillation and hyperbolic discounting is by noting the strange pattern of responsiveness that they embody. To say that an agent is responding to reasons does not mean simply that there are reasons to behave in some way and that the agent in fact acts in accordance with those reasons. It requires, moreover, that the agent's behavior is mediated by an appreciation of what the relevant reasons are (see note 12 above). As Fischer and Ravizza argued, if we heard of an agent who would desist from buying a ticket to a basketball game if the ticket were priced at 1000 dollars, and yet would go on to purchase the ticket if its price were 1001 dollars, we would naturally question whether the agent's response to the 1000 dollars-ticket scenario was in fact a reflection of reasons-responsiveness on her part. Instead, we would likely interpret the counterfactual test as evidence of anomalous, erratic behavior. What we expect to find in an agent who is actually being receptive and reactive to reasons is a sufficiently coherent pattern of responsiveness across different potential or counterfactual scenarios (Fischer and Ravizza 1998: 65 and ff.). This is something we arguably do not find, or find to a lesser degree, in an agent who undergoes the envisaged kinds of judgement or preference shift in cases of belief-oscillation and hyperbolic discounting.
} 
decrease in control involved in addiction. We have now seen, moreover, that it also constitutes a powerful tool for framing a story about control-undermining factors. This stems from the fact that reasons-responsiveness is a high-level property, thus allowing for a doubly pluralistic account. On the one hand, it is compatible with a story comprising a reference to both internal and external factors as potentially relevant to the degree of control enjoyed by an agent at any particular time. On the other hand, it is well suited to frame an account of psychological processes in addiction that is sufficiently abstract to be consistent with various proposals concerning the exact nature of the anomaly involved. An account along these lines is, I submit, particularly well poised to provide a unifying picture of the multiply variable class of addictive behaviors.

5. A brief note on implications for moral responsibility

Now that the main outlines of my proposed view are in place, I turn to briefly consider a couple of important related issues. The first one concerns some of the potential implications of the view presented here for attributions of moral responsibility in the accountability sense (Watson, 1996). This is a complex issue that deserves more careful consideration than I am presently able to offer, but a brief note may be in order to get a slightly fuller picture of the view of control presented here.

Consider the case of Max, the Unexpected Babysitter.

Max runs a small hotel on the road to a distant location. On a particular night, the only people in the hotel are Max and two passengers, a mother and her small child. Unexpectedly, the mother passes out and has to be taken in a rush to the hospital, leaving Max as the only available adult around to look after the child while she is gone. In spite of that he decides to get very high that particular night, risking potential harm to the child if she happened to need his assistance.

Barring any further consideration, we clearly feel that Max is responsible in the accountability sense - and is indeed blameworthy - for risking potential harm to the child. But imagine we then learn that he suffers from severe opioid addiction (and suppose further that he came to acquire his addiction as a result of justified medical treatment in an entirely nonculpable way, thus blocking all routes for a case of derivative responsibility). 
Plausibly, reflection upon this situation yields a pair of apparently conflicting intuitions. On the one hand, we may feel that Max's condition as an addict offers some sort of mitigating consideration for his behavior, such that taking it into account we would consider him to be less blameworthy than if he had not suffered from such a condition. Contrast his case with the case of Pat, who behaves exactly like Max in exactly the same circumstances, but who does not suffer from an addiction. Intuitively, Max would appear to be comparatively less blameworthy than Pat. The rationale for this may be that it was much more difficult for Max to avoid using drugs that particular night than it was for Pat (Coates \& Swenson, 2013; Nelkin, 2016), and the fact that Max enjoys a lesser degree of control over his drug-related behavior will plausibly be part of the explanation of the greater difficulty faced by him in attempting to refrain from the relevant behaviors that night. If we think of moral responsibility as co-varying with degrees of control (and we assume further that the decrease in control came about in a non-culpable way), then the view of decreased control I presented in the previous sections is able to provide a straightforward explanation for the intuition that addiction can in some cases function as a mitigating consideration when we consider degrees of blameworthiness.

The other apparently conflicting intuition that we get from Max's case is that, even if we acknowledge mitigating circumstances, that does not eliminate the sense that he is blameworthy for having risked potential harm to the child. Insofar as he retains a degree of control over his behavior under the present view, that explains why we feel it would not be improper to see him as a target of the normative demand not to behave in that way. To put it differently, our reaction to the case is not the one we would have if Max had risked harm to the child as the result of an epileptic seizure or some other event that were occurring properly out of his control.

The foregoing observations leave untouched of course many complicated issues concerning moral responsibility in addiction. A proper treatment would require, among other things, dealing with responsibility in the attributability sense, giving a serious consideration to appeals to derivative responsibility and possibly also to the steps the agent could have taken to overcome his condition. And there is always the possibility that ordinary intuitions may need to be revised in the light of relevant evidence, so the intuitiveness of a given framework may only be counted as presumptive evidence in its favor. Nevertheless, it seems highly plausible that an appeal to addiction may function as a mitigating but not as a fully excusing consideration when it comes to appraising the blameworthiness of an agent for morally reprehensible behavior. If that much is accepted, then it speaks in favor of the view presented 
in the foregoing sections that it is able to explain the rationale for that intuition in a way that yields the expected results.

\section{Two objections}

\subsection{Thresholds}

An integral part of my proposed view is that addiction involves a decrease but not a complete loss of control over drug-related behaviors. But a worry may arise concerning the need to impose minimum threshold conditions for a form of control to be at all worthy of the name. Going back to the case of Mark and John, it may seem that the correct way to describe an agent that would only refrain from drinking when faced with the prospect of imminent death is as someone how does not really enjoy any significant control over his drinking behavior. This worry is further strengthened by the fact that theories of reasons-responsiveness typically do impose minimum thresholds of responsiveness to reasons for control to be present in the relevant sense. The upshot would be then that, contrary to my claim, many addicts possibly do not enjoy any significant form of control over the relevant sorts of behavior after all.

I think that once the fully scalar nature of reasons-responsiveness is allowed into the picture, the need to set a threshold somewhere along the spectrum of responsiveness may or may not present itself in accordance with various pragmatic considerations at hand in different domains (Sinnott-Armstrong \& Pickard, 2013). By the same token, it is these pragmatic, interest-relative considerations that will guide us to establish that threshold at a particular point in the scale rather than on another, once the need to settle on a demarcation arises. In particular, it seems likely that attributions of moral or legal responsibility do require minimum threshold conditions for control, as someone enjoying truly little control would likely be regarded as an improper target of moral or legal demands.

But it does not follow from this that there is not a cogent concept of control that we can think of as fully scalar. If we equate control and reason-responsiveness, and if, more concretely, we allow that it in all likelihood all addicts would be responsive to some reasons to refrain from using in any particular instance, there is no reason to deny that we are tracking a real property in the agent's behavior when we attribute her a certain degree of control, however minimal it may be and irrespective of whether it amounts to the kind of control required for moral or legal responsibility. In other words, there is no reason to deny that there 
is $a$ sense of control in which even the most severely addicted agents enjoy some degree of it, such that their behavioral profile may be informatively distinguished from a condition of literal, pure compulsion involving a total absence of control.

This reply assumes for the sake of argument that there are cases of addiction where the retained degree of responsiveness to reasons is so minimal that the question may arise concerning whether a significant form of control is present at all. That is, however, an assumption that would be hard to substantiate on empirical grounds, at least with regard to typical cases of addiction. Even if we accepted that responsiveness to reasons has to reach some minimum threshold in order for the agent's behavioral profile to exhibit a form of control worthy of the name, it may nevertheless be the case that typical cases of addiction do not involve a decrease in reasons-responsiveness as severe as to fall below the requisite threshold.

\subsection{Recovering addicts}

Another possible worry is that how many reasons an agent would respond to may come apart from how difficult or costly it is for the agent to respond to those reasons. Difficulty and costliness, according to this objection, may signal a lack of control not explained by the present account. To illustrate, imagine a person who always manages to respond to relevant reasons and avoid drugs but who does so only by exerting tremendous effort and concentration, at the expense of other activities and possibly also enduring the discomfort of cravings. Such an agent, the objection goes, would manage to behave in a reasons-responsive way, and yet possess what could be described as an addicted disposition ${ }^{21}$.

Consider, for instance, the cases of many recovering addicts who manage to stay sober for long periods of time and yet continue to experience strong urges to use drugs in a way that people without a prior history of addiction do not. Admittedly, there is something anomalous in such motivational make-up. In a typical case, the recovering addict will continue to experience cravings for drugs during a significant period of time, her thoughts will likely be recurrently drawn to images related to drug-use and refraining from using drugs will require a great deal of effort or be in other ways difficult or costly ${ }^{22}$. And there may be grounds to

\footnotetext{
${ }^{21}$ I thank an anonymous referee for bringing this problem to my attention.

${ }^{22}$ Notice that effortfulness and difficulty or costliness for the agent may come apart in important ways. In particular, many self-regulation strategies available to people struggling to overcome addiction - for instance, distancing themselves from certain kinds of situations, places, and relations - may be difficult
} 
continue to describe such agents as addicts as, for instance, the relapse rates for recovering addicts are remarkably high (Kirshenbaum, Olsen, \& Bickel, 2009). It has often been proposed, on that account, that addiction is a chronic condition that a person may continue to suffer even when she is presently able to refrain from using drugs (e.g., McLellan, Lewis, O'Brien, \& Kleber, 2000). Moreover, some people in that condition may choose to continue to identify themselves as addicts, as this may in some cases help dealing with the costs involved in exercises of self-control and to remain alert to the high risk of relapse.

All this notwithstanding, there are some important differences between the condition of the recovering addict and that of the currently using addict that need to be accounted for. Recall that, on most therapeutic definitions, an addict is precisely someone who continues to engage in the relevant behaviors (see, for instance, the definition in the DSM-V quoted in note 2 above). And the key difference between the successful recovering addict and the currently using addict is very plausibly thought of as a difference in control. Even if the recovering addict is only able to refrain by means of effortful or otherwise costly strategies, that she is in fact able to do so marks a crucial difference in her agential profile as compared to that of the currently using addict. In that regard, the account laid out in the foregoing sections is well poised to make sense of that difference in control in terms of degrees of reasonsresponsiveness. The successful recovering addict manages to be both receptive and reactive to sufficient reasons to refrain from using in a way that the currently using addict is not. And here too it is an advantage of the present account that it is framed in terms of a high-level property as reasons-responsiveness, as it allows us to capture the relevant difference despite the continuing anomaly in the motivational profile that the recovering addict instantiates. Such an approach would not be open, for instance, to an account of addiction framed in terms of strong appetites or desires.

In sum, the decreased reasons-responsiveness approach proposed here is meant primarily as a way to capture the particular sort of impairment of control that is experienced by the currently using addict. However, a related thought might be able to shed some light into the condition of recovering addicts as well. Consider, for instance, the case of the agent who knows that if she were to step into that bar or go to that party, she would not manage to remain sober and who, as a result, decides to stay home tonight. What she knows is something

to pursue and result in significant costs for the agent, without involving in a prominent way the phenomenology of mental effort that usually goes with exertions of willpower. Moreover, there are reasons to think that strategies of the former sort may be more effective than relying in willpower to directly inhibit wayward desires (Snoek, Levy, \& Kennett, 2016). 
about how she would behave in certain potential or counterfactual scenarios that can easily be captured in terms of reasons-responsiveness. And those potential or counterfactual scenarios are plausibly pointing to a sense in which such an agent is in fact less reasons-responsive than someone who is not equally susceptible to the relevant kinds of impulses, even when she in fact manages to stay sober by distancing herself from the circumstances under which her control might be more easily compromised.

\section{Conclusion}

In the foregoing sections I presented an account of degrees of control as degrees of reasonsresponsiveness that aims to provide a clear concept in terms of which to think about loss control in addiction. And I sketched further an account of control-undermining factors in addiction that is consonant with my proposed view of control. A key feature of this account is that is consistent with a pluralistic stance towards a range of explanatory models currently available in the theoretical landscape. As I stressed earlier, this seems the most promising strategy to arrive at a unified story concerning the different types and cases of addictive behaviors.

I did not claim, however, to have uncovered the essential core underlying the many manifestations of addiction. Or, for that matter, to have settled whether addiction is in the end a cogent kind that is unified in a sufficiently deep sense. Whether that is the case is not something we could determine by philosophical reflection alone. But I have provided some conceptual tools in terms of which such a unified story can be told. And importantly, even if the empirical evidence tipped the balance in the end towards the direction of eliminativism about addiction as a unified kind, the framework provided here might still prove to be useful for thinking about the relevant succeeding notions ${ }^{23}$.

\footnotetext{
${ }^{23}$ I thank Santiago Amaya, Emily Bingeman, Cami Koepke, Dana Nelkin, Diana Pérez, Fernando Rudy Hiller, Manuel Vargas and two anonymous referees for their comments on previous drafts of this paper. This publication was made possible through the support of a grant from the John Templeton Foundation, grant \#61255 project name 'LATAM Free Will, Agency and Responsibility'. The opinions expressed in this publication are those of the author and do not necessarily reflect the views of the John Templeton Foundation.
} 


\section{References}

Ainslie, G. (2000). A Research-Based Theory of Addictive Motivation. Law and Philosophy, 19, 77-115.

American Psychiatric Association, -APA- (2013). Diagnostic and Statistical Manual of Mental Disorders (5th ed.). Washington D.C.: American Psychiatric Association.

Anton, R. (2000). Obsessive-compulsive aspects of craving: development of the Obsessive Compulsive Drinking Scale. Addiction, 95(Supplement 2), S211-S217.

Bickel, W. K., Koffarnus, M. N., Moody, L., \& Wilson, A. G. (2014). The behavioral- and neuroeconomic process of temporal discounting: A candidate behavioral marker of addiction. Neuropharmacology, 76, 518-527.

Brink, D., \& Nelkin, D. (2013). Fairness and the Architecture of Responsibility. Oxford Studies in Agency and Responsibility, 1, 284-313.

Charland, L. (2002). Cynthia's Dilemma: Consenting to Heroin Prescription. The American Journal of Bioethics, 2(2), 37-47.

Clarke, R. (1994). Doing What One Wants Less: A Reappraisal Of The Law Of Desire. Pacific Philosophical Quarterly, 75, 1-10.

Clarke, R. (2009). Dispositions, Abilities to Act, and Free Will: The New Dispositionalism. Mind, 118(470), 323-351.

Clarke, R. (2020). It's Up to You. The Monist, 103 (3), 328-341.

Coates, D. J., \& Swenson, P. (2013). Reasons-responsiveness and Degrees of Responsibility. Philosophical Studies, 165, 629-645.

Elliot, C. (2002). Who Holds the Leash? The American Journal of Bioethics, 2(2), 48.

Elster, J. (1999). Strong Feelings. Emotion, Addiction, and Human Behavior. Cambridge, Mass.: MIT Press.

Fischer, J. M., \& Ravizza, M. (1998). Resposibility and Control. A Theory of Moral Responsibility. Cambridge: Cambridge University Press.

Flanagan, O. (2013). Phenomenal Authority. The Epistemic Authority of Alcoholics Anonymous. In N. Levy, Addiction and Self-Control.Perspectives from Philosophy, Psychology (pp. 67-93). Oxford: Oxford University Press.

Flanagan, O. (2018). Identity and Addiction. In H. Pickard, \& S. Ahmed, The Routledge Handbook of Philosophy and Science of Addiction (pp. 77-89). New York: Routledge.

Frankfurt, H. (1971). Freedom of the Will and the Concept of a Person. The Journal of Philosophy, 68(1), 5-20.

Hänninen, V., \& Koski-Jännes, A. (1999). Narratives of recovery from addictive behaviours. Addiction, 94(12), 1837-1848.

Hart, C. (2013). High Price. New York: Harper Perennial. 
Hart, C., Haney, M., Foltin, R. W., \& Fischman, M. W. (2000). Alternative Reinforcers Differentially Modify Cocaine Self-Administration by Humans. Behavioural Pharmacology, 11(1), 87-91.

Heather, N. (1998). A Conceptual Framework for Explaining Drug Addiction. Journal of Psychopharmacology, 12(1), 3-7.

Henden, E. (2018). Addiction as a Disorder of Self-Control. In H. Pickard, \& S. Ahmed, The Routledge Handbook of Philosophy and Science of Addiction (pp. 45-53). New York: Routledge.

Heyman, G. M. (2009). Addiction. A Disorder of Choice. Cambridge, Mass. : Harvard University Press.

Holton, R. (2009). Willing, Wanting, Waiting. Oxford: Oxford University Press.

Holton, R., \& Berridge, K. (2013). Addiction Between Compulsion and Choice. In N. Levy, Addiction and Self-Control.Perspectives from Philosophy, Psychology, and Neuroscience (pp. 239-268). Oxford: Oxford University Press.

Kalivas, P., \& Volkow, N. (2005). The Neural Basis of Addiction: A Pathology of Motivation and Choice. American Journal of Psychiatry, 162, 1403-1413.

Kennett, J. (2013). Just Say No? Addiction and the Elements of Self-Control. In N. Levy, Addiction and Self-Control. Perspectives from Philosophy, Psychology, and Neuroscience (pp. 144-163). Oxford: Oxford University Press.

Kessler, R. C., Chiu, W. T., Demler, O., \& Walters, E. E. (2005). Prevalence, Severity, and Comorbidity of Twelve-month DSM-IV Disorders in the National Comorbidity Survey Replication. Archives of General Psychiatry, 62(6), 617-627.

Khantzian, E. J. (2003). Understanding Addictive Vulnerability: An Evolving Psychodynamic Perspective. Neuro-Psychoanalysis, 5(1), 5-21.

Kirshenbaum, A. P., Olsen, D. M., \& Bickel, W. K. (2009). A quantitative review of the ubiquitous relapse curve. Journal of Substance Abuse Treatment, 36, 8-17.

Kurzban, R., Duckworth, A., Kable, J. W., \& Myers, J. (2013). An opportunity cost model of subjective effort and task performance. Behavioral and Brain Sciences, 36, 661-726.

Levy, N. (2010). Addiction and Compulsion. In T. O'Connor, \& C. Sandis, A Companion to the Philosophy of Action (pp. 267-273). Oxford: Wiley-Blackwell.

Levy, N. (2014). Addiction as a disorder of belief. Biology and Philosophy, 29(3), 337-355.

Levy, N. (2018). Addiction: the belief oscillation hypothesis. In H. Pickard, \& S. Ahmed, The Routledge Handbook of Philosophy and Science of Addiction (pp. 54-62). New York: Routledge.

Lewis, M. (2017). Addiction and the Brain: Development, Not Disease. Neuroethics, 10, 7-18.

Loewenstein, G. (1996). Out of Control: Visceral Influences on Behavior. Organizational Behavior And Human Decision Processes, 65(3), 272-292.

Loewenstein, G. (1999). A Visceral Account of Addiction. In J. Elster, \& O. Skog, Getting Hooked: Rationality and Addiction. Cambridge: Cambridge University Press. 
McKenna, M. (2013). Reasons-Responsiveness, Agents, and Mechanisms. Oxford Studies in Agency and Responsibility, 1, 151-84.

McLellan, A., Lewis, D., O'Brien, C., \& Kleber, H. (2000). Drug dependence, a chronic medical illness: implications for treatment, insurance, and outcomes evaluation. Journal of the American Medical Association, 284(13), 1689-95.

Mele, A. (1990). Irresistible Desires. NOÛS, 24(3), 455-472.

National Institute on Drug Abuse, -NIDA- (2014). Drugs, Brains and Behavior. The Science of Addiction. Bethesda, MD: National Institute on Drug Abuse.

Nelkin, D. (2011). Making Sense of Freedom and Responsibility. Oxford: Oxford University Press.

Nelkin, D. (2016). Difficulty and Degrees of Moral Praiseworthiness and Blameworthiness. NOÛS, 50(2), 356-378.

Petry, N. M., Alessi, S. M., Olmstead, T. A., Rash, C. J., \& Zajac, K. (2017). Contingency management treatment for substance use disorders: How far has it come, and where does it need to go? Psychology of Addictive Behaviors, 31(8), 897-906.

Pickard, H. (2012). The Purpose in Chronic Addiction. AJOB Neuroscience, 3(2), 40-49.

Pickard, H. (2017). Responsibility without Blame for Addiction. Neuroethics, 10(1), 169-180.

Pickard, H. (2018). The Puzzle of Addiction. In H. Pickard, \& S. Ahmed, The Routledge Handbook of Philosophy and Science of Addiction (pp. 9-22). New York: Routledge.

Pickard, H. (2020). Addiction and the Self. NOÛS, 1-25.

Robinson, T. E., \& Berridge, K. C. (1993). The neural basis of drug craving: an incentivesensitization theory of addiction. Brain Research Reviews, 18(3), 247-91.

Robinson, T. E., \& Berridge, K. C. (2008). The incentive sensitization theory of addiction: some current issues. Philosophical Transactions of the Royal Society of London. Series B, Biological Sciences, 363, 3137-3146.

Sinnott-Armstrong, W. (2013). Are Addicts Responsible? In N. Levy, Addiction and SelfControl.Perspectives from Philosophy, Psychology, and Neuroscience (pp. 122-143). Oxford: Oxford University Pres.

Sinnott-Armstrong, W., \& Pickard, H. (2013). What is Addiction? In K. Fulford, M. Davies, R. Gipps, G. Graham, J. Sadler, G. Stanghellini, \& T. Thornton, The Oxford Handbook of Philosophy and Psychiatry. Oxford: Oxford University Press.

Skinner, M. D., \& Aubin, H.-J. (2010). Craving's place in addiction theory: Contributions of the major models. Neuroscience and Biobehavioral Reviews, 34, 606-623.

Snoek, A., Levy, N., \& Kennett, J. (2016). Strong-willed but not successful: The importance of strategies in recovery from addiction. Addictive Behaviors Reports, 4, 102-107.

Sripada, C. (2018). Addiction and Fallibility. The Journal of Philosophy, 115(11), 569-587. 
Sripada, C. (forthcoming). Loss of Control In Addiction: The Search For An Adequate Theory And The Case For Intellectual Humility. In J. M. Doris, \& M. Vargas, Oxford Handbook of Moral Psychology. Oxford: Oxford University Press.

Vargas, M. (2013). Building Better Beings. A Theory of Moral Responsibility. Oxford: Oxford University Press.

Vargas, M. (2020). Negligence and Social Self-Governance. In A. Mele, Surrounding SelfControl. Oxford: Oxford University Press.

Verdejo-Garcia, A. (2018). Decision-making Dysfunctions in Addiction. In H. Pickard, \& S. Ahmed, The Routledge Handbook of Philosophy and Science of Addiction (pp. 339-350). New York: Routledge.

Volkow, N., Koob, G., \& McLellan, T. (2016). Neurobiologic Advances from the Brain Disease Model of Addiction. The New England Journal of Medicine, 374(4), 363-371.

Wallace, R. J. (1994). Responsibility and the Moral Sentiments. Cambridge, Mass.: Harvard University Press.

Wallace, R. J. (1999). Addiction as Defect of the Will: Some Philosophical Reflections. Law and Philosophy, 18(6), 621-654.

Watson, G. (1977). Skepticism about Weakness of Will. The Philosophical Review, 86(3), 316339.

Watson, G. (1996). Two Faces of Responsibility. Philosophical Topics, 24(2), 227-248.

Watson, G. (1999). Disordered Appetites: Addiction, Compulsion and Dependence. In J. Elster, Addiction. Entries and Exits (pp. 3-28). New York: Russel Sage Foundation.

Whittle, A. (2010). Dispositional Abilities. Philosophers' Imprint, 10(12), 2-23.

World Health Organization, -WHO- (2014). Neuroscience of Psychoactive Substance Use and Dependence. Geneva, Switzerland: World Health Organization. 